\title{
Persepsi peternak babi terhadap kinerja penyuluh pertanian lapangan (PPL) di Kecamatan Sonder Kabupaten Minahasa
}

\author{
A. K. Rintjap, G. D. Lenzun, E. Wantasen \\ Fakultas Peternakan Universitas Sam Ratulangi Manado95119 \\ *Korespondensi (corresponding author): annekerintjap@unsrat.ac.id
}

\begin{abstract}
ABSTRAK
Penelitian ini bertujuan Untuk mengetahui Persepsi Peternak Babi Terhadap KIinerja Penyuluh Pertanian Lapangan (PPL) di Kecamatan Sonder Kabupaten Minahasa. Penelitian ini dilakukan bdengan metode survey, pengamatan langsung dan wawancara dengan menggunakan kuesioner. Penentuan sampel dilakukan secara purposive sampling dengan kriteria terapat peternak babi yang terbanyak dan yang mendapatkan penyuluhan dari penyuluh pertanian lapangan (PPL). Jenis data adalah data primer dan data sekunder serta menggunakan rumus Slovin dan skala Likert. Persepsi peternak terhadap kinerja penyuluh di tinjau dari aspek kualitas layanan adalah setuju, dari aspek responsifitas adalah tidak setujuh, dan dari aspek responsibilitas adalah raguragu.
\end{abstract}

Kata kunci :Persepsi Peternak, Kinerja PPL, Skala Likert.

\begin{abstract}
ABTRACT
THE PERCEPTION OF PIG FARMERS ON THE PERFORMANCE OF FIELD AGRICULTURAL EXTENDERS IN SONDER DISTRICT, MINAHASA DISTRICT. This study aims to determine the perception of pig breeders on the performance of field agricultural extension officers (PPL) in Sonder District, Minahasa Regency. This research was conducted using survey methods, direct observation and interviews using a questionnaire. The sample was determined by purposive sampling with the criteria that the largest number of pig breeders received counseling from field agricultural extension workers (PPL). Types of data are primary data and secondary data and use the Slovin formula and Likert scale. Farmers 'perceptions of extension workers' performance were reviewed from the aspect of service quality is agree, from the aspect of responsiveness is not the same, and from the aspect responsibility is doubtful.
\end{abstract}

Keywords: $\quad$ Farmer Perception, PPL Performance, Likert Scale. 


\section{PENDAHULUAN}

Langkah efektif yang dapat ditempuh dalam rangka mempercapat laju proses pembangunan peternakan adalah dengan melakukan pengembangan peternak melalui program pembangunan peternakan. Program peternakan yang dimaksud merupakan rangkaian upaya perwujudan pembangunan peternakan yang mampu meningkatkan kesejahteraan peternak., agar dapat berjalan lancar membutuhkan adanyan kegiatan penyuluhan atau pendidikan tentang pembangunan.

Peran penyuluhan pertanian dipengaruhi oleh persepsi peternak terhadap kinerja penyuluh. Unsur-unsur kinerja PPL terdiri dari, pengetahuan PPL, keterampilan PPL, peranan PPL, karakteristik PPL, norma dan nilai PPL didalam berkomunikasi dengan peternak babi. Persepsi peternak terhadap kinerja penyuluh baik, berarti penyuluh tersebut sudah menjalankan fungsinya dengan baik. Begitu juga sebaliknya, jika persepsi peternak terhadap kinerja penyuluh kurang baik, maka penyuluh harus memperbaiki kinerjanya (Sucihatiningsih dan Waridin, 2010; Ahmad, 2017)

Dan berdasarkan semua hal yang telah dikemukakan maka dilakukan penelitian yang bertujuan untuk mengkaji apakah keberhasilan para peternak babi ada campur tangan dari para Penyuluh Pertanian Lapangan (PPL). Oleh karena itu, perlu dilakukan penelitianapakah persepsi peternak babi terhadap kinerja PPL di kecamatan Sonder Kabupaten Minahasa. Untuk melihat suatu kerja atau efektifitas penyuluh tidak hanya dilihat dari hasil yang telah diperoleh dari program penyuluhan tersebut tetapi juga dapat dilihat dari bagaimana para peternak menilai kinerja PPL dengan berbagai argumen masing-masing dari beberapa peternak. (Prawiranegara et al., 2015; Rintjap et al., 2017 ; Jahi dan Leilani, 2011; Hubeis, 2010)
Tujuan penelitian untuk menganalissis persepsi dari peternak babi terhadap kinerja yang telah di lakukan oleh Penyuluh Pertanian Lapangan (PPL) di Kecamatan Sonder Kabupaten Minahasa.

\section{METODE PENELITIAN}

\section{Tempat dan waktu penelitian}

Penelitian ini sudah dilaksanakan di Kecamatan Sonder pada bulan Desember 2020.

\section{Jenis data dan sumber data}

Jenis data yang digunakan dalam penelitian ini adalah data primer dan data sekunder. Data primer diperoleh langsung dari peternak dengan cara mengajukan pertanyaan dari kuisioner yang telah disediakan, sedangkan data sekunder adalah data yang diperoleh dari buku-buku yang relevan dengan penelitian atau jurnal-jurnal serta instansi pemerintah yang terkait dengan penelitian ini.

\section{Penentuan sampel}

Penelitian ini dilakukan dengan metode survei dan pengamatan langsung ke lapangan. Lokasi penelitian dilakukan secara purposive sampling dengan kriteria terdapat peternak babi yang terbanyak dan yang mendapatkan penyuluhan dari PPL.Jumlah peternak babi di Kecamatan Sonder.

Bias dilihat pada Tabel 2, maka lokasi yang di jadikan tempat penelitian berdasarkan kriteria adalah Desa Talikuran Satu, Desa Tounelet Satu, Desa Kauneran, Desa Talikuran dan Desa Tounelet. Penentuan sampel dilakukan dengan menggunakan rumus Slovin. Dalam perhitungan sampel, berikut rumus Slovin yang dikemukakan oleh Talibo et al. (2017).

$$
n=\frac{N}{1+N(e)^{2}}
$$


Dimana:

$\mathrm{n}=$ Ukuran sampel

$\mathrm{N}=$ Ukuran populasi

$\mathrm{e}=$ kelonggaran ketidak telitian pengambilan sampel yang ditoleransi $5 \%$

Berdasarkan penjelasan di atas, maka dengan menggunakan rumus slovin ukuran sampel dapat dihitung sebagai berikut (Sugiarto, 2017)

$$
\begin{gathered}
n=\frac{N}{1+N(e)^{2}}=\frac{19}{1+19(5 \%)^{2}}=\frac{19}{3,5} \\
=5,42=5
\end{gathered}
$$

\section{Definisi Variabel dan Pengukuran}

1. Kinerja PPL adalah tingkat pencapaian hasil pelaksanaan kegiatan dari penyuluh dengan menggunaan indikator kualitas layanan, responsivitas dan responsibilitas.

2. Responsivitas adalah cara penyuluh mengidentifikasi kebutuhan sarana prasarana dalam proses penyuluhan

3. Responsibilitas adalah cara penyuluh memberi semangat dan motivasi pertnak.

4. Kualitas layanan adalah kepuasaan terhadap layanan penyuluhan bimbingan, pembinaan, pendampingan yang dilakukan oleh penyuluh, dan kepuasaan terhadap komunikasi (berbicara, bergaul, berdiskusi) yang dilakukan oleh penyuluh.

5. Persepsi adalah tanggapan (penerimaan) langsung dari peternak.

Skala pengukuran pada penelitian ini menggunakan Skala Likert. Skala Likert adalah suatu skala piskometrik yang umum di gunakan dalam kuisioner, dan merupakan skala yang paling banyak digunakan dalam riset survei Pengukuran yang digunakan untuk mengukur jawaban dari responden digunakan skala Likert.Langkah-langkah dalam membuat Skala Likert dalam penelitian ini yaitu :

1. Mengumpulkan pernyataan atau pertanyaan yang sesuai dengan sikap yang akan diukur. Identifikasi secara jelas sikap tersebut positif atau negatif.

2. Memberikan pernyataan-pernyataan tersebut kepada responden yang dijadikan sampel penelitian.

3. Responden diminta untuk mengisi setiap pilihan pernyataan atau pertanyaan dengan menggunakan kuisioner.

4. Respon tersebut akan di analisis dengan cara memberi skor pada masing-masing pilihan jawaban yaitu dengan rentang skor 1 sampai 5 (Sugiarto, 2017) jika:

1. SS : Sangat Setuju

2. S : Setuju

3. RG : Ragu-ragu

4. TS : Tidak Setuju

5. STS : Sangat Tidak Setuju

Total skor yang didapatkan dari masingmasing responden adalah penjumlahan dari skor masing-masing pilihan jawaban responden tersebut. Respon jawaban dianalisis untuk mengetahui perbedaan nyata pilihan jawaban responden.

\section{Analisis data}

Setelah data yang diperoleh dilapangan terkumpul sesuai dengan jumlah yang diinginkan, maka proses selanjutnya adalah menganalisis data. Analisis data yang dilakukan dalam penelitian ini yaitu dengan menggunakan teknik analisis kuantitatif dan menggunakan Skala Likert.

Menurut Sugiarto (2017) Skala likert digunakan untuk mengukur sikap, pendapat dan persepsi seseorang atau sekelompok orang tentang fenomena sosial. Dalam penelitian ini, Skala Likert digunakan untuk mengukur sikap dan persepsi peternak babi terhadap kinerja PPL.

Berdasarkan jawaban dari responden selanjutnya akan diperoleh satu kecenderungan atas jawaban responden tersebut. Kuisioner yang dibagikan dilakukan 
menggunakan Skala Likert. Maka perhitungan indeks jawaban responden dilakukan dengan rumus sebagai berikut:

Nilai Indeks $=(\mathrm{F} 1 \times 1)+(\mathrm{F} 2 \times 2)+(\mathrm{F} 3 \times 3)+$ $(\mathrm{F} 4 \mathrm{x} 4)+(\mathrm{F} 5 \times 5) / 5$

Dimana :

F1 : Frekuensi jawaban responden yang menjawab 1 (Sangat Tidak Setuju)

F2 : Frekuensi jawaban responden yang menjawab 2 (Tidak Setuju)

F3 : Frekuensi jawaban responden yang menjawab 3 (Ragu-ragu)

F4 : Frekuensi jawaban responden yang menjawab 4 (Setuju)

F5 : Frekuensi jawaban responden yang menjawab 5 (Sangat Setuju).

\section{HASIL DAN PEMBAHASAN}

\section{Keadaan umum lokasi penelitian}

Kecamatan Sonder terletak di Kabupaten Minahasa yang terdiri dari 19 Desa yaitu Desa Kolongan Atas, Kolongan Atas Satu, Kolongan Atas Dua, Tounelet, Tounelet Satu, Talikuran, Talikuran Satu, Sendangan, Sendangan Satu, Sawangan, Rambunan Amian, Rambunan, Leilem, Leilem Dua, Leilem Tiga. Kauneran, Kauneran Satu, Tincep, dan Timbukar.

Kecamatan Sonder memiliki dua musim yaitu musim kering dan musim hujan. Pada musim hujan, biasanya turun rata-rata sebanyak 23 hari setiap tahun. Dengan ratarata curah hujan $244.53 \mathrm{~mm}$ per bulan. Pada

musim kering, curah hujan kurang dari 13 hari, dengan rata-rata curah hujan $\mathrm{cm}$ per bulan. Dengan rata-rata kelembapan udara absolute maksimum per bulan 93,93\% dan rata-rata kelembaban minimum per bulan $80,50 \%$.

Potensi-potensi yang ada di Kecamatan Sonder adalah :
1. Sektor Pertanian: Sub Sektor Tanaman Pangan Padi Sawah dan Jagung

2. Sektor Perkebuan: Tanaman Cengkeh, Tanamah Kayu

3. Sektor Peternakan: Ayam ras/buras, babi

4. Sektor Perikanan: Tambak Ikan Mujair dan Mas

5. Sektor Industri: Industri Mebel

6. Sektor Pariwisata

7. Wisata Alam Air Terjun Tincep,

8. Wisata Olah Raga Arung Jeram Timbukar

9. Wisata Taman Eman (PT. Indra Wisata Sonder)

10. Wisata Kuliner (RM Terapung, RM Sonder Indah, RM Arma)

Batas-batas Wilayah Kecamatan Sonder

- Utara : Kota Tomohon

- Timur : Kecamatan Remboken

- Selatan: Kecamatan Kawangkoan

- Barat : Kecamatan Suluun Tareran (Kabupaten Minahasa Selatan)

\section{Persepsi peternak terhadap kinerja penyuluh dari aspek kualitas layanan}

Kualitas layanan dalam penelitian ini ditinjau dari aspek materi, media dan metode. Dari Tabel 3 dapat dilihat bahwa total skor untuk persepsi peternak babi terhadap kinerja PPL dengan indikator komunikasi media, metode dan materi diperoleh 75 skor dengan kategori sangat setuju.Hal ini berarti bahwa menurut jawaban responden sebagian merasa susah Sangat Puas dengan kinerja PPL dengan indikator layanan komunikasi media, metode dan materi.

\section{Persepsi peternak terhadap kinerja penyuluh dari aspek responsifitas}

Responsifitas dalam penelitian ini ditinjau dari aspek sarana prasarana, 
pendampingan, pembinaa dan pembimbingan.

Fungsi penyediaan sarana prasarana adalah untuk melayani dan mendorong terwujudnya lingkungan permukiman dan lingkungan usaha yang optimal sesuai dengan fungsinya

Dari Tabel 4 dapat dilihat bahwa total skor untuk persepsi peternak babi terhadap kinerja PPL dengan indikator penyediaan sarana-prasarana diperoleh 24 skor dengan kategori tidak setuju. Hal ini berarti bahwa menurut jawaban responden sebagian merasa Tidak setuju/tidak puas dengan mengenai terhadap kinerja PPL.

Dalam hal ini, PPL bertanggung jawab dan berperan sebagai pendamping teknis untuk petani/peternak dalam membantu masyarakat petani/peternak dalam usaha mereka dalam meningkatkan kesejahteraan melalui peningkatan hasil produksi usaha mereka .

Dari Tabel 5 dapat dilihat bahwa total skor untuk persepsi peternak babi terhadap kinerja PPL dengan pemberian pendampingan diperoleh 34 skor dengan kategori tidak setuju. Hal ini berarti bahwa menurut jawaban responden sebagian merasa Tidak setuju/tidak puas dengan pemberian pendampingan. Berdasarkan peraturan Menteri Pertanian Indonesia nomor 273/Kpts/OT.160/4/2007 tentang pedoman pembinaan kelembagaan petani.

Dari Tabel 6 dapat dilihat bahwa total skor untuk persepsi peternak babi terhadap kinerja PPL dengan indikator pembinaan diperoleh 24 skor dengan kategori ragu-ragu. Hal ini berarti bahwa menurut jawaban responden sebagian merasa kurang puas dengan pemberian pembinaan. Hal ini sejalan dengan penelitian sebelumnya yang megatakan bahwa petani masih bersikap ragu terhadap hasil yang akan di capai mereka dalam menerapkan teknologi baru yang di tawarkan oleh penyuluh (Sundari et al., 2015; Far, 2014)

Dari Tabel 7 dapat dilihat bahwa total skor untuk persepsi peternak babi terhadap kinerja PPL dengan indikator pembimbingan diperoleh 36 skor dengan kategori ragu-ragu.

Hal ini berarti bahwa menurut jawaban responden sebagian merasa Tidak puas dengan indikator pembimbingan. Tujuan utama dari penyuluhan pertanian adalah memberikan pembimbingan (Hakim, 2012; Mardikanto, 2011)

\section{Persepsi peternak perhadap kinerja penyuluh dari aspek responsibilitas}

Responsibilitas dalam penelitian ini ditinjau dari aspek motivasi dan kepuasan. Motivasi yang ada pada seseorang merupakan kekuatan pendorong yang akan mewujudkan suatu perilaku guna mencapai kepuasan dirinya (Amanah, 2013).

Dari Tabel 8 dapat dilihat bahwa total skor untuk persepsi peternak babi terhadap kinerja PPL dengan indikator motivasi terhadap peternak diperoleh 39 skor dengan kategori ragu-ragu.Hal ini berarti bahwa menurut jawaban responden sebagian merasa belum terlalu puas dengan indikator motivasi oleh PPL terhadap peternak babi yang ada. Kepuasan atau ketidakpuasan peternak berhubungan dengan perbedaan antara harapan dan kinerja yang diterima atau dirasakan oleh peternak (Rintjap et al., 2013; Rintjap 2015).

Dari Tabel 9 dapat dilihat bahwa total skor untuk persepsi peternak babi denganindikator kepuasan peternak terhadap PPL diperoleh 39 skor dengan kategori raguragu.Hal ini berarti bahwa menurut jawaban responden sebagian merasa belum terlalu puas dengan layanan PPL terhadap peternak babi yang 
Tabel 1. Jumlah Peternak Babi di Kecamatan Sonder

\begin{tabular}{|c|c|c|}
\hline No & Desa & Peternak babi \\
\hline 1 & Kauneran & 23 \\
\hline 2 & Kauneran Satu & 14 \\
\hline 3 & Kolongan Atas & 14 \\
\hline 4 & Kolongan Atas Satu & 10 \\
\hline 5 & Kolongan Atas Dua & 12 \\
\hline 6 & Leilem & 4 \\
\hline 7 & Leilem Dua & 2 \\
\hline 8 & Leilem Tiga & 3 \\
\hline 9 & Rambunan & 10 \\
\hline 10 & Rambunan Amian & 8 \\
\hline 11 & Sendangan & 10 \\
\hline 12 & Sendangan Satu & 9 \\
\hline 13 & Sawangan & 4 \\
\hline 14 & Talikuran & 18 \\
\hline 15 & Talikuran Satu & 31 \\
\hline 16 & Timbukar & 10 \\
\hline 17 & Tincep & 7 \\
\hline 18 & Tounelet & 18 \\
\hline \multirow[t]{2}{*}{19} & Tounelet Satu & 29 \\
\hline & Total & 236 \\
\hline
\end{tabular}

Sumber : BP3K Kecamatan Sonder

Tabel 2. Jumlah responden.

\begin{tabular}{clc}
\hline No & \multicolumn{1}{c}{ Desa Terpilih } & Jumlah responden (orang) \\
\hline 1 & Talikuran Satu & 9 \\
2 & Tounelet Satu & 8 \\
3 & Kauneran & 6 \\
4 & Talikuran & 5 \\
5 & Tounelet & 5 \\
\hline & Total & 33 \\
\hline
\end{tabular}

Tabel 3. Komunikasi Penyuluh Terkait Media, Metode, dan Materi

\begin{tabular}{cclcc}
\hline Indikator & $\begin{array}{c}\text { Frekuensi } \\
\text { (Orang) }\end{array}$ & Katagori Jawaban & Nilai & Jumlah \\
\hline & 15 & Sangat Setuju & 5 & 75 \\
Persepsi peternak terhadap & 7 & Setuju & 4 & 28 \\
kinerja Penyuluh dari aspek & 8 & Ragu-ragu & 3 & 24 \\
Media, Metode dan Materi & - & Tidak Setuju & 2 & - \\
& - & Sangat Tidak Setuju & 1 & - \\
\hline Total & 30 & & & 127 \\
\hline
\end{tabular}


Tabel 4. Indikator sarana prasarana

\begin{tabular}{cclcc}
\hline Indikator & $\begin{array}{c}\text { Frekuensi } \\
\text { (Orang) }\end{array}$ & Katagori Jawaban & Nilai & Jumlah \\
\hline & - & Sangat Setuju & 5 & - \\
Penyediaan sarana prasarana & - & Setuju & 4 & - \\
& 5 & Ragu-ragu & 3 & 15 \\
& 12 & Tidak Setuju & 2 & 24 \\
& 13 & Sangat Tidak Setuju & 1 & 13 \\
\hline Total & 30 & & & 52 \\
\hline
\end{tabular}

Tabel 5. Indikator Pendampingan

\begin{tabular}{cclcc}
\hline Indikator & $\begin{array}{c}\text { Frekuensi } \\
\text { (Orang) }\end{array}$ & \multicolumn{1}{c}{ Katagori Jawaban } & Nilai & Jumlah \\
& 1 & Sangat Setuju & 5 & 5 \\
Pendampingan & - & Setuju & 4 & - \\
& 4 & Ragu-ragu & 3 & 12 \\
& 17 & Tidak Setuju & 2 & 34 \\
& 8 & Sangat Tidak Setuju & 1 & 8 \\
\hline Total & 30 & & & 56 \\
\hline
\end{tabular}

Tabel 6. Indikator Pembinaan

\begin{tabular}{cclcc}
\hline Indikator & $\begin{array}{c}\text { Frekuensi } \\
\text { (Orang) }\end{array}$ & Katagori Jawaban & Nilai & Jumlah \\
\hline \multirow{3}{*}{ Pembinaan } & 2 & Sangat Setuju & 5 & 10 \\
& 5 & Setuju & 4 & 20 \\
& 8 & Ragu-ragu & 3 & 24 \\
& 6 & Tidak Setuju & 2 & 12 \\
\hline Total & 9 & Sangat Tidak Setuju & 1 & 9 \\
\hline
\end{tabular}

Tabel 7. Indikator Pembimbingan

\begin{tabular}{cclcc}
\hline Indikator & $\begin{array}{c}\text { Frekuensi } \\
\text { (Orang) }\end{array}$ & Katagori Jawaban & Nilai & Jumlah \\
& 3 & Sangat Setuju & 5 & 15 \\
Pembimbingan & 1 & Setuju & 4 & 4 \\
& 12 & Ragu-ragu & 3 & 36 \\
& 3 & Tidak Setuju & 2 & 6 \\
& 11 & Sangat Tidak Setuju & 1 & 11 \\
\hline Total & 30 & & & 72 \\
\hline
\end{tabular}


Tabel 8. Indikator Motivasi

\begin{tabular}{cclcc}
\hline Indikator & $\begin{array}{c}\text { Frekuensi } \\
\text { (Orang) }\end{array}$ & \multicolumn{1}{c}{ Katagori Jawaban } & Nilai & Jumlah \\
& 2 & Sangat Setuju & 5 & 10 \\
Motivasi & 6 & Setuju & 4 & 24 \\
& 13 & Ragu-ragu & 3 & 39 \\
& 2 & Tidak Setuju & 2 & 4 \\
& 7 & Sangat Tidak Setuju & 1 & 7 \\
\hline Total & 30 & & & 84 \\
\hline
\end{tabular}

Tabel 9. Indikator Kepuasan terhadap kinerja Penyuluh

\begin{tabular}{cclcc}
\hline \multicolumn{1}{c}{ Indikator } & $\begin{array}{c}\text { Frekuensi } \\
\text { (Orang) }\end{array}$ & Katagori Jawaban & Nilai & Jumlah \\
\hline \multirow{3}{*}{ Kepuasan Terhadap Kinerja } & 1 & Sangat Setuju & 5 & 5 \\
Penyuluh & 4 & Setuju & 4 & 16 \\
& 13 & Ragu-ragu & 3 & 39 \\
& 3 & Tidak Setuju & 2 & 6 \\
& 9 & Sangat Tidak Setuju & 1 & 9 \\
\hline & 30 & & & 75 \\
\hline
\end{tabular}

KESIMPULAN

Persepsi peternak terhadap kinerja penyuluh di tinjau dari aspek kualitas layanan adalah setuju, dari aspek responsifitas adalah tidak setuju, dan dari aspek responsibilitas adalah ragu-ragu

\section{DAFTAR PUSTAKA}

Ahmad A, 2017. Model penyuluhan partisipatif terhadap respon adopsi petani di Kabupaten Sinjai. Jurnal Agrominansia, 2 (1): 223 - 234.

Amanah, S. 2013. Makna penyuluhan dan transformasi perilaku manusia. Jurnal Penyuluhan. 3 (1): 63-67.

Far, R. A. F. 2014. Respon petani terhadap penerapan metode penyuluhan pertanian di kota Ambon Provinsi Maluku. Jurnal Budidaya Pertanian. 10 (1) :48-51.

Hakim, L. 2012. Pemberdayaan Petani Sayuran: Kasus Petani Sayuran di Sulawesi Selatan. Disertasi. Sekolah
Pasca sarjana. Institut Pertanian Bogor. Bogor.

Hubeis. M. 2010. Prospek Usaha Kecil dalam Wadah Indikator Bisnis, Galia Indonesia, Jakarta.

Jahi, A, dan A. Leilani. 2011. Kinerja penyuluh pertanian di beberapa kabupaten, Propensi Jawa Barat. Jurnal Penyuluh. 2 ( 2): 57-62

Mondy N 2015. Manajemen Pengembangan Sumber Daya Manusia Pustaka Pelajar: Yogyakarta.

Merdikanto, T. 2011. System Penyuluh Pertanian. Surakata: Penerbit Universitas Sebelas Maret.

Rintjap A K., B Hartono, D. Wisadirana, dan F.H. Elly 2013. Model Komunikasi Dalam Pengembangan Usaha Ternak Sapi Potong (Studi Pada Kelompok Peternak Sapi Potong Di Kabupaten Minahasa Provinsi Sulewesi Utara). Disertasi Doktor. Program Pasca 
sarjana Fakultas Peternakan Unversitas Brawijaya. Malang.

Rintjap A.K 2015 Efektifitas komunikasi dalam penerimaan informasi pada kelompok peternak sapi potong di Kecamatan Remboken Kabupaten Minahasa. Seminar Nasional Masyarakat Biodiversitas Indonesia. Jogyakarta.

Rintjap A, K., F. S. Oley dan S.O.B. Lombogia. 2017. Peranan penyuluh untuk pemberdayaan kelompok pada pengembangan peternakan sapi potong di desa Tondegesan 2 Kecamatan Kawangkoan Kabupaten Minahasa. Seminar Nasional Pengembangan Agribisnis Peternakan Untuk Memperkuat Ekonomi Pedesaan di Indonesia Denpasar-Bali

Sugiarto. 2017. Metodologi Penelitian Bisnis. Yogyakarta: Penerbit ANDI.

Prawiranegara D., Sumardjo, D.P. Lubis, dan S. Harijati. 2015. Strengthening role of farmer institution in enhance of innovation capability based on ict in west java province, Indonesia. International Journal of Humanities and Social Science, 5(12): 128-136.

Sucihatiningsih D.W.P dan Waridin. 2010. Model penguatan kapasitas kelembagaan penyuluh pertanian dalam meningkatkan kinerja usaha tani melalui transaction cost. Jurnal Ekonomi Pembangunan, 11(1): 13-29.

Sugiarto. 2017. Metodologi Penelitian Bisnis. Yogyakarta: Penerbit ANDI.

Sundari, A.H., Yusra, dan Nurliza. 2015. Peran penyuluh pertanian terhadap peningkatan produksi usahatani di Kabupaten Pontianak. Jurnal Social Economic of Agriculture, 4 (1): 26-31.

Talibo. R, B.F.J. Sondakh, A.S. Sajow, dan J. Lainawa, 2017. Analisis persepsi petani peternak sapi potong terhadap peran penyuluh di Kecamatan Sangkub Kabupaten Bolaang Mongondow Utara. Jurnal Zootec, 37(2): 513-525. 
